\title{
Zeros of Sections of the Zeta Function. II
}

\section{By Robert Spira*}

1. Recapitulation. Paul Turán proved theorems connecting the locations of zeros of the Dirichlet polynomials

$$
\zeta_{N}(s)=\sum_{n=1}^{N} n^{-s}
$$

with the Riemann hypothesis. Let $s=\sigma+i t$. One such theorem is that if all the zeros of every $\zeta_{N}(s)$ had real parts $\sigma \leqq 1$, then the Riemann hypothesis would be true. Unfortunately, this very simple condition, which could perhaps have been worked with in an inductive fashion, was shown by Haselgrove [1] to fail infinitely often. In part I of this paper (Spira [2]), a description was given of a calculation of zeros of $\zeta_{N}(s)$ for various $N$ up to $10^{10}$. No zero with $\sigma>1$ was found.

In this concluding part, we apply in Section 2 generalizations of basic theorems of Bohr to $\zeta_{N}(s)$, and find g.l.b. $\left|\zeta_{N}(s)\right|$ for $\sigma \geqq 1$ and $N \leqq 5$. In Section 3 we discuss a confirmation of Haselgrove's proof, and report on related calculations. In Section 4 , we describe machine proofs that $\zeta_{N}(s)$ has no zeros with $\sigma \geqq 1$ for $N \leqq 9$, and proofs of the existence of such zeros for a variety of small $N$ starting with $N=19$. Finally, we discuss our attempts at finding such zeros.

2. Applications of Bohr's Theorems. Let $p_{j}$ be the $j$ th prime, so $p_{1}=2$. For $n>$ 1 , let $r_{n, j}$ be the highest power of $p_{j}$ dividing $n$, and let $q_{n}$ be the index of the largest prime dividing $n$. We then can write (1) as

$$
\zeta_{N}(s)=\sum_{n=1}^{N} n^{-\sigma} \exp \left(-i t\left(r_{n, 1} \log 2+r_{n, 2} \log 3+\cdots+r_{n, q_{n}} \log p_{q_{n}}\right)\right)
$$

where we interpret the sum in parentheses as 0 when $n=1$. Introducing the new variables $x_{j}=t \log p_{j}$, we now define the companion function of $\zeta_{N}(s)$ :

$$
F_{N}=F_{N}\left(\sigma, x_{1}, x_{2}, \cdots\right)=\sum_{n=1}^{N} n^{-\sigma} \exp \left(-i\left(r_{n, 1} x_{1}+r_{n, 2} x_{2}+\cdots+r_{n, q_{n}} x_{q_{n}}\right)\right) .
$$

Since the $\log p_{j}$ are linearly independent over the rationals, and the $r_{n, j}$ are integers, we can apply generalizations (Spira [3]) of theorems of Bohr [4]. We can conclude first of all the set of values of $\zeta_{N}(s)$ for $\sigma \in(a, \infty)$ and $t \in(-\infty, \infty)$ is identical with the set of values of $F_{N}\left(\sigma, x_{1}, \cdots\right)$ where $\sigma \in(a, \infty)$ and each $x_{j}$ runs independently over $[0,2 \pi)$. Thus, taking $a=1, \zeta_{N}(s)=0$ for some $\sigma>1$ and some $t$ if and only if $F_{N}\left(\sigma, x_{1}, \cdots\right)=0$ for some (possibly different) $\sigma>1$, and some values of the variables $x_{1}, x_{2}, \cdots$. We remark also that if $\zeta_{N}(s)$ has one zero with $\sigma>1$, it has infinitely many (Spira [3]). Secondly, we can conclude that the values of

Received February 13, 1967.

* Present address: Michigan State University, East Lansing, Michigan. 
$F_{N}\left(\sigma, x_{1}, \cdots\right)$ where $\sigma$ runs over a closed interval, and the $x_{j}$ 's run independently over $[0,2 \pi)$, form a closed set. Thus, for the $\sigma$-interval $[1,2]$, the distance of this set to the origin is a well-defined constant, $d_{N}$.

Now, from the last two lines of p. 542 of I, we have that for $\sigma>1$,

$$
\left|\zeta_{N}(s)\right| \geqq 1-2^{-\sigma}(\sigma+1) /(\sigma-1)
$$

and this last function increases with $\sigma$. At $\sigma=2$, its value is $1 / 4$, so for $\sigma \geqq 2$, $\left|\zeta_{N}(s)\right| \geqq 1 / 4$. Hence, for $\sigma>2,\left|F_{N}\right| \geqq 1 / 4$, and if $d_{N} \leqq 1 / 4, d_{N}$ is the minimum distance of $F_{N}$ to the origin for all $\sigma \geqq 1$. For $5 \leqq N \leqq 50$ it turns out that $d_{N} \leqq$ $1 / 4$, but it is also true that for $N \leqq 4, d_{N}$ is the minimum distance for all $\sigma \geqq 1$.

To discuss these $N \leqq 4$ cases, and for the sequel, we define:

$$
\pi_{N}=\text { the set of primes } p \text { satisfying } N / 2<p \leqq N,
$$

$$
\begin{aligned}
\zeta_{N}^{*}(s) & =\sum_{n=1 ; n}^{N \bigoplus_{\pi_{N}}} n^{-s}, \quad \pi_{N}(s)=\sum_{n \in \pi_{N}} n^{-s}, \\
F_{N}{ }^{*} & =F_{N}\left(\sigma, x_{1}, \cdots\right)=\text { the companion function of } \zeta_{N}^{*}(s), \\
P_{N} & =P_{N}\left(\sigma_{1}, x_{1}, \cdots\right)=\text { the companion function of } \pi_{N}(s) .
\end{aligned}
$$

We have $\zeta_{N}(s)=\zeta_{N}{ }^{*}(s)+\pi_{N}(s), F_{N}=F_{N}{ }^{*}+P_{N}$. Note that $\sigma$ is the only variable $F_{N}{ }^{*}$ and $P_{N}$ have in common. The first four $\zeta_{N}^{*}(s)$ are $1,1,1,1+2^{-s}+4^{-8}$. In general, we have

$$
\begin{aligned}
& \zeta_{N}^{*}(s)=\zeta_{N-1}^{*}(s) \text { if } N \text { is a prime } \\
& \zeta_{N}^{*}(s)=\zeta_{N-1}^{*}(s)+(N / 2)^{-8}+N^{-s} \text { if } N \text { is twice a prime } \\
& \zeta_{N}^{*}(s)=\zeta_{N-1}^{*}(s)+N^{-8} \text { otherwise }
\end{aligned}
$$

and there are similar equations for $F_{N}{ }^{*}$. It is clear that the variables in $P_{N}$ can be chosen so that $P_{N}$ is a vector in any assigned direction of length $\sum_{p} \in_{\pi_{N}} p^{-\sigma}$. We avoid the general question of whether values of $\sigma, x_{1}, \cdots$ which minimize $\left|F_{N}{ }^{*}\right|$ also minimize $\left|F_{N}\right|$ after suitable selection of the variables in $P_{N}$. For $N \leqq 5$, this turns out to be true, since the minima for $\sigma \geqq 1$ of $\left|F_{N} *\right|$ lie at the extreme $\sigma=1$. The remarks above on the relations of the sets of values of $\zeta_{N}(s)$ and $F_{N}$ also carry over to the functions $\zeta_{N}{ }^{*}(s)$ and $F_{N}{ }^{*}$.

For $N=1$, it is trivial that $d_{N}=1$. A short calculation shows that for $N=2$, we obtain a minimum $d_{2}=1 / 2$ at $\sigma=1, x_{1}=\pi$, and for $N=3, d_{3}=1 / 6$ and is attained at $\sigma=1, x_{1}=x_{2}=\pi$. It is also easy to see that these three minima hold for $\sigma \geqq 1$. We sketch the calculation of $d_{4}$.

We consider first $F_{4}{ }^{*}$. We have $\left|F_{4}{ }^{*}\right| \geqq 1-2^{-\sigma}-4^{-\sigma}$, which is $>0$ for $\sigma \geqq 1$. Thus, for some $\sigma$ in $[1,3]$ and for some $x_{1}$ in $[0,2 \pi),\left|F_{4}{ }^{*}\right|$ takes on a positive minimum. In finding such $\sigma$ and $x_{1}$, we can study $g\left(\sigma, x_{1}\right)=\left|F_{4}{ }^{*}\right|^{2}$ instead of $\left|F_{4}{ }^{*}\right|$. At a minimum, we must have $\partial g / \partial x_{1}=0$, (since $g$ is periodic of period $2 \pi$ in $x_{1}$, we do not have to consider extreme values in that variable). A short calculation gives

$$
\begin{aligned}
g\left(\sigma, x_{1}\right) & =1+2^{-2 \sigma}+4^{-2 \sigma}+2^{1-\sigma}\left[1+4^{-\sigma}\right] \cos x_{1}+2 \cdot 4^{-\sigma} \cos 2 x_{1}, \\
\partial g / \partial x_{1} & =-2^{1-\sigma}\left(\sin x_{1}\right)\left[1+4^{-\sigma}+2^{2-\sigma} \cos x_{1}\right] .
\end{aligned}
$$

Thus, $\partial g / \partial x_{1}=0$ if and only if $x_{1}=0$ or $\pi$, or $\cos x_{1}=-\left(2^{\sigma}+2^{-\sigma}\right) / 4$. For $x_{1}=\pi$, 
setting $x=2^{-\sigma}$, we obtain $g(\sigma, \pi)=\left(x^{2}-x+1\right)^{2}$. It is easily seen that $x^{2}-x+1$ $>0$, and has its minimum at $x=1 / 2$ or $\sigma=1$, where $\left|F_{4}{ }^{*}\right|=3 / 4$.

For $x_{1}=0$, we obtain $g(\sigma, 0)=\left(x^{2}+x+1\right)^{2}$, which is greater than $\left(x^{2}-x+1\right)^{2}$ $(=g(\sigma, \pi))$ if $x>0$, which we can assume as $x=2^{-\sigma}$. Thus, the minimum cannot be attained for $x_{1}=0$.

In the final case, using $\cos 2 x_{1}=2 \cos ^{2} x_{1}-1$, if $\cos x_{1}=-\left(2^{\sigma}+2^{-\sigma}\right) / 4$, we obtain $\cos 2 x_{1}=\left(4^{\sigma}-6+4^{-\sigma}\right) / 8$ and $g\left(\sigma, x_{1}\right)=\frac{3}{4}\left(1-4^{-\sigma}\right)^{2}$, which is least at $\sigma=1$, and indeed gives the least possible $\left|F_{4}{ }^{*}\right|$ of $3 \sqrt{ } 3 / 8$, at $\cos x_{1}=-5 / 8$. This gives $d_{4}=(9 \sqrt{ } 3-8) / 24$ and $d_{5}=(45 \sqrt{ } 3-64) / 120$, where we choose $x_{2}$ and $x_{3}$ so that the vectors $\exp \left(-i x_{2}\right)$ and $\exp \left(-i x_{3}\right)$ point opposite to $F_{4}^{*}(1, \arccos (-5 / 8))$.

If $F_{N}\left(\sigma, x_{1}, \cdots\right)=0$, and if the appropriate Jacobian does not vanish, we can solve the equation for $\sigma$, and thus obtain a $\sigma$ interval in which $F_{N}$ vanishes. The zeros of $\zeta_{N}(s)$ will have real parts dense in this interval. The empirical results suggest the conjecture that to each $\zeta_{N}(s)$ there is a single such interval, though it could possibly arise from overlapping $F_{N} \sigma$-intervals.

If we take $F$ as the companion function of a general Dirichlet series, it is not clear what we should do about such solvability conditions, since $F$ will have infinitely many variables.

3. Calculations Related to Haselgrove's. The Dirichlet polynomial

$$
L_{N}(s)=\sum_{n=1}^{N} \frac{\lambda(n)}{n^{s}}
$$

where $\lambda(n)$ is Liouville's function, is equivalent in the sense of Bohr [4] to $\zeta_{N}(s)$, and hence assumes the same set of values in any half plane $\sigma>\sigma_{0}$. If $s$ is real and large, then $L_{N}(s)$ is near 1 . Thus, if $L_{N}(1)<0$, then there would be a real root of $L_{N}(s)$ larger than 1, and hence also a root of $\zeta_{N}(s)$ with $\sigma>1$.

The author found that $L_{N}(1)>0$ for $N \leqq 824,000$, and found $L_{293}(1)=$ $.0051122775, L_{1000}(1)=.0289948068$, values slightly different from those appearing in Turán [6]. The lowest value obtained was $L_{96862}=.00011996$. R. Sherman Lehman's [5] values of $L_{N}(0)$ for $N=200,000(200,000) 800,000$ were verified.

To study $L_{N}(1)$ further, one may use analytic expressions, derived by the calculus of residues (Haselgrove [1], Lehman [5]). Indeed, setting

$$
L_{1}(x)=\sum_{n \leqq x} \frac{\lambda(n)}{n}
$$

the expression

$$
B_{T}(u)=\frac{-1}{\zeta\left(\frac{1}{2}\right)}+\sum_{\left|\gamma_{n}\right|<T} \frac{\zeta\left(2 \rho_{n}\right)}{\left(\rho_{n}-1\right) \zeta^{\prime}\left(\rho_{n}\right)} \exp \left(i \gamma_{n} u\right),
$$

where $\rho_{n}=\frac{1}{2}+i \gamma_{n}$ are roots of $\zeta(s)$, under various unproved hypotheses, can be shown to represent $e^{u / 2} L_{1}\left(e^{u}\right)$, with some blurring. The focusing improves as $T$ increases. For example, for $T=200$ and $u \leqq 2$, one can readily see rather sharp changes (without a Gibbs effect) as $L_{1}(x)$ makes a step. Lehman [5] used a function similar to (14) to successfully guess where $L(x)=\sum_{n \leqq x} \lambda(n)$ changed sign.

An expression the same as (14) but with the factor $\left(1-\gamma_{n} / T\right)$ inside the sum was used by Haselgrove to show that $L_{1}(x)$ is negative infinitely often. We designate 
this sum by $B_{T}^{*}(u)$. For corresponding sums for $L(x)$ we use the notation $A_{T}(u)$ and $A_{T}{ }^{*}(u)$, as used by Lehman [5]. Finally, by $C_{T}(u)$ and $C_{T}{ }^{*}(u)$ we mean the corresponding sums for the function $M(x)=\sum_{n \leqq x} \mu(n)$, where $\mu(n)$ is the Möbius function. We have

$$
C_{T}(u)=\sum_{\left|\gamma_{n}\right|<T} \frac{\exp \left(i \gamma_{n} u\right)}{\rho_{n} \zeta^{\prime}\left(\rho_{n}\right)},
$$

which represents, hopefully, $e^{-u / 2} M\left(e^{u}\right)$. Formulas for $A_{T}(u)$ and $A_{T}{ }^{*}(u)$ can be found in Lehman [5], and for $B_{T}^{*}(u)$ and $C_{T}{ }^{*}(u)$ in Haselgrove [1].

All six of these functions were calculated in double precision for $T=100, u=$ $0(.01) 500$, and for $T=200,500$, and 1000 in selected ranges. The coefficients for these functions were calculated in double precision, calculating first improved $\gamma_{n}$ from the $6 \mathrm{D}$ values in Haselgrove and Miller [7]. We first discuss the tables in Haselgrove [1]. Write $\alpha_{n}=\zeta\left(2 \rho_{n}\right) / \rho_{n} \zeta^{\prime}\left(\rho_{n}\right)$. In Table I, the $\gamma_{n}$ are correct to within 3 units in the 10th significant figure. For the first six $\left|\alpha_{n}\right|$, terminal digits 19,8,5,3,2,993, were obtained rather than $23,6,8,5,4,878$. For $n=9,15,18,34,48$ the terminal digits $4,4,6,6,3$ were obtained rather than $5,3,5,7,4$. The quantity $\left(p h \alpha_{n}\right) / \pi$ was not checked. The values of $A_{1000}^{*}(u)$ in Table II were confirmed within 1 unit except for the five values starting with 831.837 , which are two units low. Also, the value at 831.857 was found to be -.06320 . In Lehman's [5] paper the value $A_{1000}(814.492)$ was found to have terminal digit 0 , and $A_{1000}(831.847)$ was found to be .0049448 .

Two new places were found where $A_{T}^{*}(u)>0: A_{1000}^{*}(310.8276)=.0109$, $A_{1000}^{*}(384.690)=.0316$. High maxima also occur at $u=33.495,44.591$ and 214.404 .

For $L_{1}(x)$, the author found that $B_{1000}^{*}(853.853)=-.0321$ and $B_{1000}^{*}(996.980)=$ -.0450 and $B_{1000}^{*}(996.981)=-.0457$, confirming Haselgrove's proof. It was also found that $B_{1000}^{*}(171.4938)=-.0009$ and $B_{1000}^{*}(331.9602)=-.0170$, giving two new places where this function is negative. Low minima occur at $u=43.897,54.624$, 124.843, 188.830, and 437.758.

To disprove Mertens hypothesis it would be sufficient to find $u$ and $T$ such that $\left|C_{T}^{*}(u)\right|>1$. No such values were found. Table I gives places where $\left|C_{1000}^{*}(u)\right|$ rises above .5.

TABLE I. Approximate Values for $e^{-u / 2} M\left(e^{u}\right)$

\begin{tabular}{c|c||c|c}
\hline$u$ & $C_{1000}^{*}(u)$ & $u$ & $C_{1000}^{*}(u)$ \\
\hline 22.7730 & +.5003 & 441.5100 & +.5145 \\
\hline 43.8965 & -.5199 & 480.6430 & +.5069 \\
\hline 97.5260 & +.5355 & 814.4910 & +.5061 \\
\hline 310.8258 & +.5301 & 553.852 & -.6027 \\
\hline
\end{tabular}

4. Machine proofs. We first describe the proofs that $\zeta_{N}(s) \neq 0$ for $\sigma \geqq 1, N \leqq 9$. The idea of such a proof is, for one variable, based on the formulas

$$
\left|f\left(x_{0}+h\right)\right| \geqq\left|f\left(x_{0}\right)\right|-\max |h| \cdot \max \left|f^{\prime}(\xi)\right|,
$$




$$
\left|f\left(x_{0}+h\right)\right| \geqq\left|f\left(x_{0}\right)\right|-\max |h|\left|f^{\prime}\left(x_{0}\right)\right|-\left(\max |h|^{2} / 2 !\right) \max \left|f^{\prime \prime}(\xi)\right|,
$$

which are easily derivable from the Taylor's expansion under suitable restrictions on $f$. Thus, from formula (16), if $\left|f^{\prime}(\xi)\right|$ is suitably bounded, and $f\left(x_{0}\right) \neq 0$, we can conclude that $f(x) \neq 0$ for a small interval about $x_{0}$. Formula (17) is useful when $|f(x)|$ has a small minimum, as in the cases we consider. We then get some help from $\left|f^{\prime}\left(x_{0}\right)\right|$ being small near the minimum, and from the $|h|^{2}$ in the next term. These formulas easily generalize to the case of $f$ being a real or complex function of several real variables. Roundoff also must be taken into account.

In our particular case, we can take advantage of the special nature of our functions $F_{N}$, and consider only the variables appearing in $F_{N}{ }^{*}$. If we take the variables $\sigma, x_{1}, \cdots$, to lie in a cube $C$, we have at any point in $C$,

$$
\left|F_{N}\right| \geqq\left|F_{N}{ }^{*}\right|-\left|P_{N}\right| \geqq \underset{C}{\text { g.l.b. }}\left|F_{N}{ }^{*}\right|-\underset{C}{\text { l.u.b. }}\left|P_{N}\right| \text {. }
$$

Thus, $\left|F_{N}\right|>0$ in $C$ provided g.l.b.c $\left|F_{N}{ }^{*}\right|>$ l.u b.c $\left|P_{N}\right|\left(=\sum_{p} \in_{\pi_{N}} p^{-\min \sigma}\right)$. Now we can apply formulas of the type (16) or (17). Write $F_{N}{ }^{*}=u+i v$. A formula corresponding to (16) is

$$
\begin{aligned}
& \left|F_{N}^{*}\left(\sigma+h, x_{1}+h_{1}, \cdots\right)\right| \\
& \geqq\left|F_{N}^{*}\left(\sigma, x_{1}, \cdots\right)\right|-\max |h|\left[\max \left|\frac{\partial u}{\partial \sigma}\right|+\max \left|\frac{\partial v}{\partial \sigma}\right|\right] \\
& \quad-\max \left|h_{j}\right|\left[\sum_{i}\left(\max \left|\frac{\partial u}{\partial x_{i}}\right|+\max \left|\frac{\partial v}{\partial x_{i}}\right|\right)\right],
\end{aligned}
$$

and one corresponding to (17) is

$$
\begin{aligned}
\left|F_{N}^{*}\left(\sigma+h, x_{1}+h_{1}, \cdots\right)\right| \geqq & \left|F_{N}^{*}\left(\sigma, x_{1}, \cdots\right)\right| \\
& -\max |h|\left[\left|\frac{\partial u}{\partial \sigma}\left(\sigma, x_{1}, \cdots\right)+i \frac{\partial v}{\partial \sigma}\left(\sigma, x_{1}, \cdots\right)\right|\right] \\
& -\max \left|h_{j}\right|\left[\sum_{i}\left|\frac{\partial u}{\partial x_{i}}\left(\sigma, x_{1}, \cdots\right)+i \frac{\partial v}{\partial x_{i}}\left(\sigma, x_{1}, \cdots\right)\right|\right] \\
& -\frac{\max |h|^{2}}{2 !}\left[\max \left|\frac{\partial^{2} u}{\partial \sigma^{2}}\right|+\max \left|\frac{\partial^{2} v}{\partial \sigma^{2}}\right|\right] \\
& -\frac{\max \left|h_{j}^{2}\right|}{2 !}\left[\sum_{i, j}\left(\max \left|\frac{\partial^{2} u}{\partial x_{i} \partial x_{j}}\right|+\max \left|\frac{\partial^{2} v}{\partial x_{i} \partial x_{j}}\right|\right)\right] \\
& -\max \left|h h_{j}\right|\left[\sum_{i}\left(\max \left|\frac{\partial^{2} u}{\partial \sigma \partial x_{i}}\right|+\max \left|\frac{\partial^{2} v}{\partial \sigma \partial x_{i}}\right|\right)\right] .
\end{aligned}
$$

It was not possible to avoid using (20). The expressions in (20) can be simplified. We have, writing $\pi_{N}{ }^{*}$ as $[1, N]-\pi_{N}$,

$$
\max \left|\frac{\partial u}{\partial \sigma}\right|+\max \left|\frac{\partial v}{\partial \sigma}\right| \leqq 2 \sum_{n \in N_{N}^{*}}(\log n) n^{-\min \sigma}
$$

and using the notation of (2), 


$$
\sum_{i}\left(\max \left|\frac{\partial u}{\partial x_{i}}\right|+\max \left|\frac{\partial v}{\partial x_{i}}\right|\right) \leqq 2 \sum_{n \in \pi_{N}^{*}}\left(r_{n, 1}+r_{n, 2}+\cdots+r_{n, q_{n}}\right) n^{-\min \sigma}
$$

For formula (20) we can use

$$
\begin{gathered}
\max \left|\frac{\partial^{2} u}{\partial \sigma^{2}}\right|+\max \left|\frac{\partial^{2} v}{\partial \sigma^{2}}\right| \leqq 2 \sum_{n \in \pi_{N^{*}}}(\log n)^{2} n^{-\min \sigma} \\
\sum_{i, j}\left(\max \left|\frac{\partial^{2} u}{\partial x_{i} \partial x_{j}}\right|+\max \left|\frac{\partial^{2} v}{\partial x_{i} \partial x_{j}}\right|\right) \leqq 2 \sum_{n \in \pi_{N^{*}}}\left(r_{n, 1}+\cdots+r_{n, q n}\right)^{2} n^{-\min \sigma}, \\
\sum_{i}\left(\max \left|\frac{\partial^{2} u}{\partial \sigma \partial x_{i}}\right|+\max \left|\frac{\partial^{2} v}{\partial \sigma \partial x_{i}}\right|\right) \leqq 2 \sum_{n \in \pi_{N}^{*}}(\log n)\left(r_{n, 1}+\cdots+r_{n, q_{n}}\right) n^{-\min \sigma}
\end{gathered}
$$

To save computation, the machine proof was attempted simultaneously for those $N$ 's for which the $F_{N}{ }^{*}$ have the same number of variables $x_{j}$. The process of proof starts with the cube $\sigma:[1,2], x_{j}:[0,2 \pi], j=1, \cdots$. One could limit one of the $x_{j}$ 's to $[0, \pi]$, since $\left|F_{N}\left(\sigma, x_{1}, x_{2}, \cdots\right)\right|=\left|F_{N}\left(\sigma, 2 \pi-x_{1}, 2 \pi-x_{2}, \cdots\right)\right|$. One breaks the cube into smaller cubes, and checks by (19) and then (20) to see if $\left|F_{N}\right|>0$ throughout each smaller cube. The smaller cubes not satisfying this are further refined. The final program used integer pair coordinates for the $x_{j}{ }^{\prime} \mathrm{s},(m, n)=2 m \pi / n$, where $n$ was chosen a power of 2 . All the cubes of a size were examined together, so that the sines and cosines could be computed just once for a given set of cubes. Also, the coordinates of $\min \left|F_{N}\right|$ were saved. If one attempts to use condition (19) alone, the number of cubes rises to an impractical level.

Table II gives results of the proofs for $N=6$ to 9 at several stages. The roundoff leeway was taken as $10^{-5}$. Column 1 contains the $\sigma$-width of the cubes. Column 2 has the number of division of $2 \pi$ for the $x_{j}$ edge length. Column 3 gives the $\sigma$-coordinate of the center of the cube with minimum $\left|F_{N}\right|$, which turned out to be the same for $N=6$ to 9 . The next three columns give $\min \left|F_{6}\right|$ and the integer first coordinates of $x_{1}$ and $x_{2}$ where this minimum was attained. The second coordinate is twice the value in column 3, (since we are calculating at the centers of cubes, the program needs a mesh half the edge). For example, in the first row, we are considering cubes of $\sigma$ width .25 , and $x_{j}$ width $2 \pi / 16$. The $\min \left|F_{6}\right|$ is .28384 and is attained at $x_{1}=11 \cdot(2 \pi / 32), x_{2}=15 \cdot(2 \pi / 32)$. The next nine columns give corresponding data for $N=7,8,9$. The last two columns give the letters $Y$ and $N$ according to whether a proof was obtained or not. The letters are in order corresponding to $N=6$ to 9 . The first of these columns gives the proof results obtained using (19) above, and the second, the results obtained using (20) also. The results in the $N=8$ columns indicate that the proof first sought out a secondary minimum, which was later calculated, and then finally found a cube where there was a lower minimum as the mesh refined. Each set of cubes was processed completely to find $\min \left|F_{N}\right|$, rejecting when possible, using the current $\min \left|F_{N}\right|$, and then a second pass made using the final values of $\min \left|F_{N}\right|$ to reject further cubes. The program also saved cubes where there was a possibility of lower min $\left|F_{N}\right|$ within the cube. The total run time was less than 20 minutes.

The $\min \left|F_{N}\right|$ in the table were recalculated in double precision, and a separate confirmatory calculation was performed along $\sigma=1$ which found $x_{1}$ and $x_{2}$ which minimized $\left|F_{N}\left(1, x_{1}, x_{2}\right)\right|$ for a mesh of $2 \pi / 650$. Values of $x_{1}, x_{2}$ which gave $\left|F_{N}\left(1, x_{1}, x_{2}\right)\right|$ slightly greater than the minimum were also saved, and studied, and 


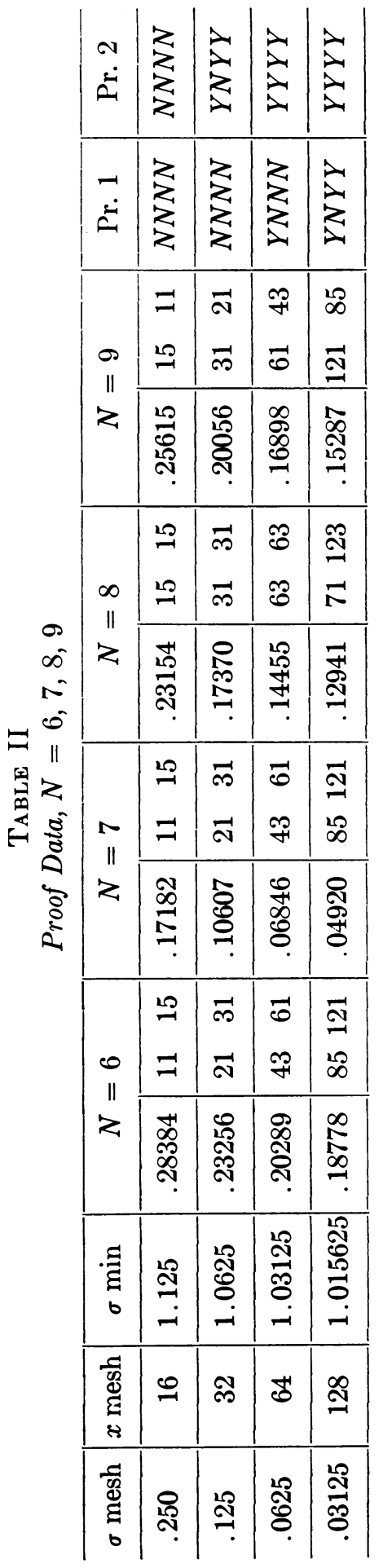




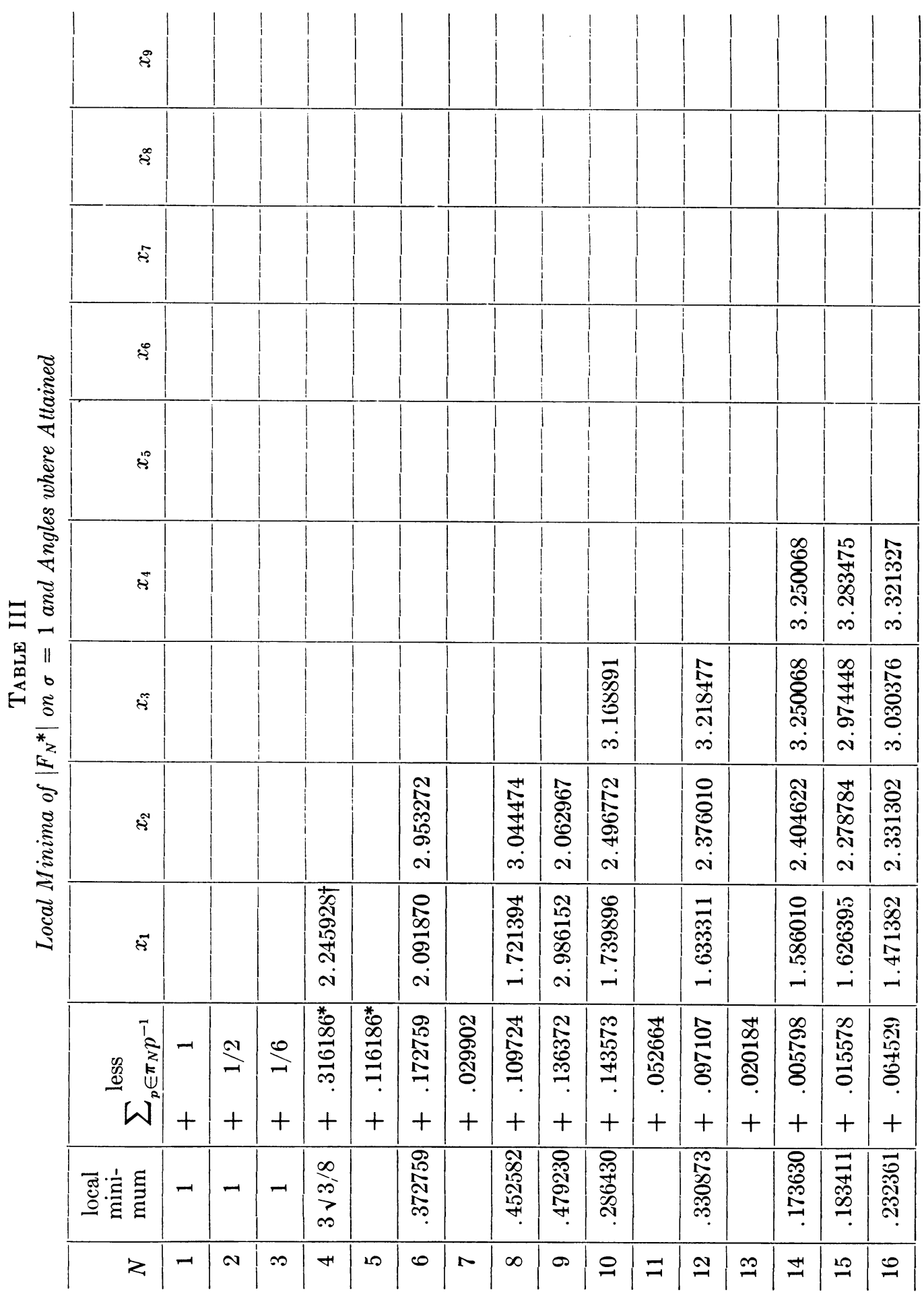




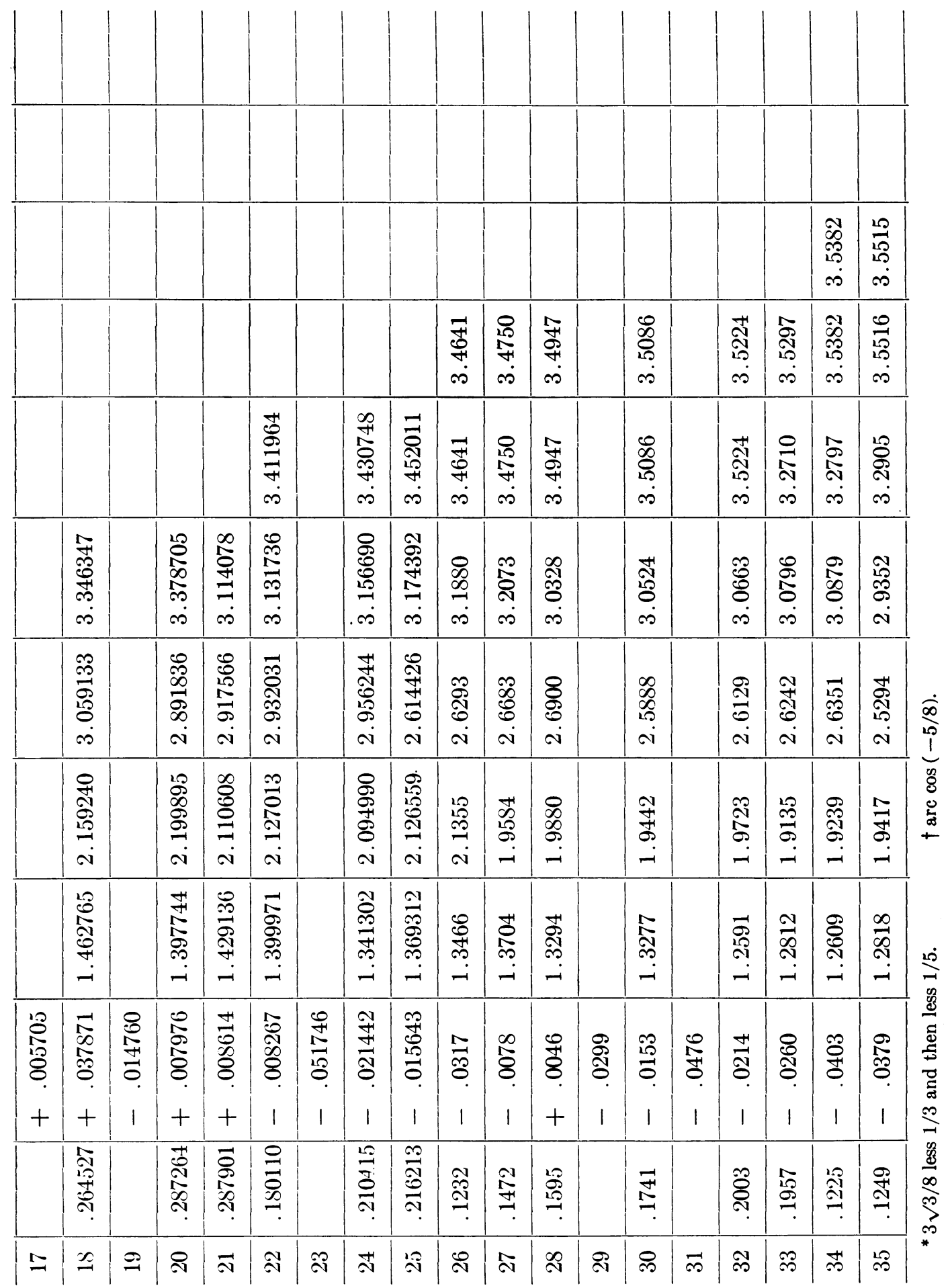




\begin{tabular}{|c|c|c|c|c|c|c|c|c|c|c|c|c|c|c|}
\hline & & & & & & & & & & $\begin{array}{l}\text { 号 } \\
\text { ஸै } \\
\dot{0}\end{array}$ & & $\begin{array}{l}\vec{\sigma} \\
\vec{\sigma} \\
\dot{\theta}\end{array}$ & 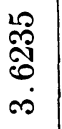 & 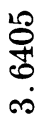 \\
\hline & & $\begin{array}{l}\text { Ŝे } \\
\text { î } \\
\text { in }\end{array}$ & 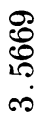 & 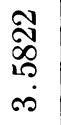 & & 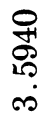 & & $\begin{array}{l}\overrightarrow{\bar{\delta}} \\
\dot{8} \\
\dot{0}\end{array}$ & 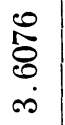 & 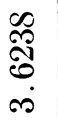 & & $\begin{array}{l}12 \\
\text { క్ర } \\
0 \\
\text { is }\end{array}$ & $\begin{array}{l}\text { N̦ } \\
\text { ปิ } \\
\text { ம் } \\
\text { ம் }\end{array}$ & 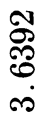 \\
\hline 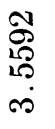 & & $\begin{array}{l}\underset{1}{n} \\
\text { in } \\
\infty\end{array}$ & $\begin{array}{l}\overrightarrow{8} \\
0 \\
0 \\
\text { ஸे }\end{array}$ & 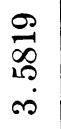 & & 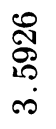 & & $\begin{array}{l}+ \\
8 \\
8 \\
0 \\
\dot{0}\end{array}$ & 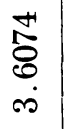 & $\begin{array}{l}\text { R्A } \\
\text { ல̂ } \\
\text { i }\end{array}$ & & 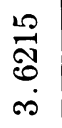 & 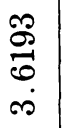 & 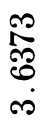 \\
\hline 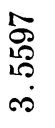 & & 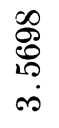 & 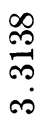 & $\begin{array}{l}\infty \\
\text { న్ } \\
\text { ஸి } \\
\text { ஸे }\end{array}$ & & 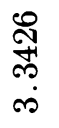 & & 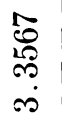 & 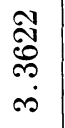 & $\begin{array}{l}\underset{N}{N} \\
\stackrel{N}{\infty}\end{array}$ & & $\underset{\infty}{\infty}$ & $\begin{array}{l}\infty \\
\stackrel{\infty}{\infty} \\
\stackrel{n}{\infty} \\
\dot{0}\end{array}$ & $\begin{array}{l}\stackrel{1}{\infty} \\
\infty \\
\infty \\
\stackrel{\infty}{0} \\
\dot{n}\end{array}$ \\
\hline 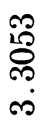 & & $\begin{array}{l}\stackrel{\oplus}{\oplus} \\
\stackrel{m}{m} \\
\text { ஸे }\end{array}$ & 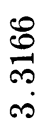 & $\begin{array}{l}\text { ర్ల్య } \\
\text { ஸे } \\
\text { ஸे }\end{array}$ & & 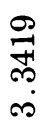 & & $\begin{array}{l}\infty \\
\mathscr{0} \\
\dot{0} \\
\dot{0}\end{array}$ & 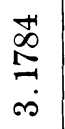 & $\begin{array}{l}\stackrel{\sim}{A} \\
\underset{\infty}{\infty} \\
\dot{\infty}\end{array}$ & & $\begin{array}{l}\stackrel{\sim}{\infty} \\
\stackrel{0}{\mathscr{2}} \\
\dot{\sim}\end{array}$ & $\begin{array}{l}\vec{F} \\
\text { Ð } \\
\dot{9}\end{array}$ & $\begin{array}{l}\overline{8} \\
\text { 尺े. } \\
\text { i. }\end{array}$ \\
\hline $\begin{array}{l}\text { I } \\
\text { of } \\
\text { o }\end{array}$ & & 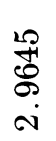 & 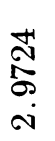 & \begin{tabular}{l}
$\infty$ \\
$\infty$ \\
$\infty$ \\
$\infty$ \\
\multirow{N}{*}{}
\end{tabular} & & $\begin{array}{l}\infty \\
\infty \\
\infty \\
\infty \\
\text { ஸे }\end{array}$ & & $\begin{array}{l}\stackrel{8}{\mathscr{S}} \\
\infty \\
\text { ஸे }\end{array}$ & $\begin{array}{l}\text { \% } \\
\text { ठ } \\
\text { o } \\
\text { i. }\end{array}$ & \begin{tabular}{l}
$\stackrel{0}{5}$ \\
8 \\
\multirow{8}{*}{} \\
N
\end{tabular} & & $\begin{array}{l}\text { Fै } \\
\text { סु } \\
\text { Ni }\end{array}$ & 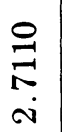 & $\underset{\text { Ni }}{\stackrel{12}{\mathbb{N}}}$ \\
\hline 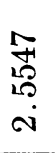 & & $\begin{array}{l}\stackrel{0}{0} \\
0 \\
\text { in } \\
\text { oi }\end{array}$ & $\begin{array}{l}\infty \\
\stackrel{\infty}{N} \\
\text { in } \\
\text { N }\end{array}$ & $\begin{array}{l}\vec{\sigma} \\
\vec{D} \\
\text { o }\end{array}$ & & $\begin{array}{l}\infty \\
\text { กิ } \\
\text { กิ } \\
\text { ๙ }\end{array}$ & & $\begin{array}{l}\underset{+}{+} \\
\text { \& } \\
\text { N }\end{array}$ & $\begin{array}{l}\vec{\sim} \\
\underset{+}{+} \\
\text { ஸे }\end{array}$ & 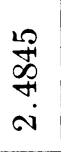 & & 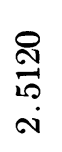 & $\begin{array}{l}\infty \\
\infty \\
\stackrel{\infty}{\infty} \\
\sim\end{array}$ & 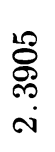 \\
\hline $\begin{array}{l}\stackrel{\infty}{\infty} \\
\infty \\
- \\
-\end{array}$ & & $\begin{array}{l}\underset{+}{\infty} \\
\infty \\
- \\
-\end{array}$ & 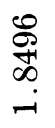 & $\begin{array}{l}\not{D} \\
0 \\
0 \\
\infty \\
-1\end{array}$ & & 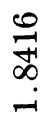 & & $\begin{array}{l}10 \\
10 \\
10 \\
-1 \\
-1\end{array}$ & $\stackrel{20}{\stackrel{\infty}{\infty}}$ & $\underset{\infty}{\infty}$ & & 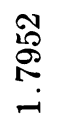 & $\begin{array}{l}\underset{\infty}{\infty} \\
\infty \\
-\end{array}$ & $\begin{array}{l}\infty \\
\infty \\
\infty \\
\infty \\
-\end{array}$ \\
\hline 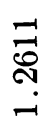 & & 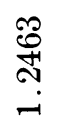 & 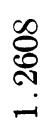 & 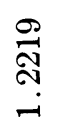 & & $\begin{array}{l}\stackrel{20}{\sigma} \\
\stackrel{\text { N }}{-1} \\
-1\end{array}$ & & $\underset{-}{\stackrel{8}{\circ}}$ & 范 & $\stackrel{\circ}{\stackrel{\overbrace{}}{\circ}}$ & & $\begin{array}{l}\stackrel{\sharp}{\circlearrowright} \\
\stackrel{-}{-}\end{array}$ & $\begin{array}{l}\mathscr{\infty} \\
\stackrel{\infty}{\infty} \\
\stackrel{-}{-}\end{array}$ & $\underset{\substack{+\infty}}{\stackrel{\infty}{-}}$ \\
\hline $\begin{array}{l}\text { 등 } \\
1\end{array}$ & $\begin{array}{c}F \\
\text { \& } \\
1\end{array}$ & 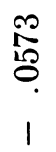 & $\begin{array}{l}\mathbb{R} \\
\mathbb{0} \\
\stackrel{0}{0} \\
1\end{array}$ & $\begin{array}{l}\text { Oै } \\
\text { ठे } \\
1\end{array}$ & 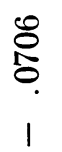 & $\begin{array}{l}\stackrel{8}{8} \\
\stackrel{8}{8} \\
0 \\
1\end{array}$ & $\begin{array}{c}\vec{\infty} \\
\infty \\
0 \\
\end{array}$ & $\begin{array}{l}2 \\
0 \\
0 \\
0 \\
1\end{array}$ & $\begin{array}{l}\stackrel{10}{0} \\
\stackrel{0}{0} \\
1\end{array}$ & $\begin{array}{l}\text { Sิ } \\
\text { 今. } \\
1\end{array}$ & $\begin{array}{l}20 \\
0 \\
0 \\
0 \\
\end{array}$ & $\begin{array}{l}\text { H } \\
\infty \\
0 \\
\end{array}$ & $\begin{array}{c}\frac{0}{\infty} \\
0 \\
1\end{array}$ & $\begin{array}{c}\vec{N} \\
\text { Iิ } \\
1\end{array}$ \\
\hline 㽟 & & $\begin{array}{l}\infty \\
\stackrel{D}{0}\end{array}$ & $\stackrel{\stackrel{9}{+}}{5}$ & $\stackrel{\circ}{\frac{8}{8}}$ & & $\stackrel{\infty}{\stackrel{0}{0}}$ & & $\underset{⿱}{\stackrel{H}{O}}$ & $\stackrel{?}{\Xi}$ & $\begin{array}{l}\text { ⿵人 } \\
\text { Oे }\end{array}$ & & 宊 & 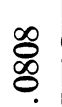 & ஜ \\
\hline ఱి & ஸ & $\infty$ & 尺্ & 우 & $F$ & $\mathscr{H}$ & $\stackrel{9}{F}$ & F & $\stackrel{19}{7}$ & $\mathscr{f}$ & F & $\stackrel{\infty}{+}$ & P্ & 옷 \\
\hline
\end{tabular}


other checking computations were performed.

It would not be difficult now to repeat the computational proof.

Minima of $\left|F_{10}^{*}\right|$ and $\left|F_{12}^{*}\right|$ were also sought with a mesh of $2 \pi / 150$, and of $\left|F_{14}^{*}\right|$ through $\left|F_{21}^{*}\right|$ with a mesh of $2 \pi / 50$. Local minima were then sought by a minimum search program, using starting values obtained from these initial searches. The searching program simply stepped each variable by a quantity $h$, halving $h$, for a number of times, as the minimum was found with mesh $h$. For $N>21$, further minima were also sought, using as starting values the quantities $x_{j}$ at which $\left|F_{N-1}^{*}\right|$ was a minimum, taking $\pi$ for the initial value of any new variable.

Table III gives the results of these computations. The $x_{j}$ are given in radians. The quantities for $N \leqq 35$ should be accurate to one unit in the last place, as they were computed in double precision. For $35<N \leqq 50$, the quantities should be correct to within 3 units in the last place. It is not claimed that the local minima are the true absolute minima of $\left|F_{N}{ }^{*}\right|$.

Since $\left|F_{N}^{*}\right| \rightarrow 1$ and $\sum_{p \in x_{N}} p^{-\sigma} \rightarrow 0$ as $\sigma \rightarrow \infty$, if we find values of the variables $x_{1}, \cdots$, so that $\left|F_{N}{ }^{*}\left(1, x_{1}, \cdots\right)\right|-\sum_{p \in \pi_{N}} 1 / p<0$, then $F_{N}\left(\sigma, x_{1}, \cdots\right)$ has a root with $\sigma>1$. Thus, from Table III, for $N=19,23$ to 27 and 29 to $50, F_{N}$ has roots with $\sigma>1$.

It is possible that such searches for minima could be speeded by using a gradient method. If this were so, one could write a general program for computing successive minima of the $\left|F_{N} *\right|$ and study whether this situation of zeros for $\zeta_{N}(s)$ for $N \geqq 29$ continues to hold. We remark that it follows from Rosser and Schoenfeld's [8] inequalities for $\sum_{p \leqq x} 1 / p$ that $\sum_{p \in \in_{N}} 1 / p$ is approximately $\log 2 / \log N$ and tends to zero as $N \rightarrow \infty$.

To find a zero of $\zeta_{19}(s)$ with $\sigma>1$, one can seek $t$ for which $t \log p_{j} \equiv x_{j}+\epsilon_{j}$ $(\bmod 2 \pi), j=1, \cdots, 4$, where the $x_{j}$ have the values of Table III for $N=19$ and $\epsilon_{j}$ is small. For $j=1$, we can make $\epsilon_{1}=0$ by choosing $t=\left(x_{1}+2 k \pi\right) / \log 2, k=0$, $\pm 1, \pm 2, \cdots$. Then for each $k$ we can check if $t \log p_{j} \equiv x_{j}(\bmod 2 \pi)$ within $\epsilon_{j}$, for $j=2,3,4$, where we preassign the $\epsilon_{j}$ 's. If one accumulated a sufficiently large number of such cases, and if $11^{-8}, 13^{-8}, 17^{-8}$ and $19^{-8}$ are randomly pointed, one could hope to find a case of a zero of $\zeta_{19}(s)$ beyond $\sigma=1$. Efforts along these lines produced the zero of $\zeta_{23}(s) .9705+i 10716133.0062$, which has real part somewhat beyond that of the lowest zero $.9325+i 1.6975$.

The calculations were performed on an IBM 7040 at the University of Tennessee Computing Center, which was aided by grants NSF-G13581 and NSF-GP4046.

Department of Mathematics

University of Tennessee

Knoxville, Tennessee

1. C. B. Haselgrove, "Disproof of a conjecture of Pólya," Mathematika, v. 5, 1958, pp. 141145. MR 21 \#3391.

2. R. SpIRA, "Zeros of sections of the zeta function. I," Math. Comp., v. 20, 1966, pp. 542-550.

3. R. SPIRA, "Sets of values of general Dirichlet series," Duke Math. J. (To appear.)

4. H. BoHr, "Zur Theorie der allgemeinen Dirichletschen Reihen," Math. Ann., v. 79, 1919, pp. 136-156.

5. R. S. Lehman, “On Liouville's functions," Math. Comp., v. 14, 1960, pp. 311-320. MR 22 \#10955.

6. P. Turán, "On some approximative Dirichlet-polynomials in the theory of the zeta function of Riemann," Danske Vid. Selsk. Mat.-Fys. Medd., v. 24, no. 17, 1948, pp. 3-26. MR $10,286$.

7. C. B. Haselgrove \& J. C. P. Miller, Tables of the Riemann Zeta Function, Royal Society Mathematical Tables, Vol. 6, Cambridge Univ. Press, New York, 1960. MR 22 \#679.

8. J. B. Rosser \& L. SCHOENFELD, "Approximate formulas for some functions of prime numbers," Illinois J. Math., v. 6, 1962, pp. 64-94. MR 25 \#1139. 